\title{
The use of service performance measurement in European hospital pharmacies
}

\author{
David Cousins
}

\section{Correspondence to} Dr David Cousins, Patient Safety Domain, NHS England, Skipton House, 80 London Road, London SE1 6LH, UK; dcousins@nhs.net and dhcousins@gmail.com

Received 25 July 2014 Accepted 29 July 2014

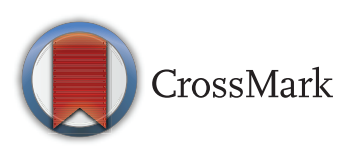

To cite: Cousins D. Eur J Hosp Pharm 2014;21: 285-287.

\section{ABSTRACT}

A survey on the use of service performance measurement was sent to European hospital pharmacies in March 2014. This was part of the preparatory work for the European Association of Hospital Pharmacists initiative to produce the European Statements of Hospital Pharmacy in May 2014. The survey form asked questions on whether service performance measures were being collected in European hospital pharmacies for four types of services: medicines distribution, medicines manufacturing, clinical services and financial services. Respondents were invited to indicate whether specified hospital pharmacy services were provided, if any measurement data had been collected in the 12 months before the survey and whether the data had been shared outside the pharmacy department. A total of 190 survey forms were completed by hospital pharmacists in 36 countries. The largest numbers of responses were from Spain (16), France (15) and Germany (15). There were single responses from Cyprus, Denmark, Luxemburg, Hungary, Macedonia, Russia and the Netherlands. Four responses did not identify the country of origin. Results for the survey indicate that the uptake of performance measurement in European hospital pharmacies is in the order: costs $>$ workload $>$ quality and safety (clinical). Apart from medicine cost data, there are relatively low rates of sharing these data outside the pharmacy department. It was noted that it is important to develop quality and safety measures at the same time as measures for cost and workload. Reductions in costs and increases in workload should not be at the expense of quality and safety.

\section{INTRODUCTION}

Performance measurement of healthcare services is important to indicate the range of services, workload, costs, quality, safety and clinical outcomes (where possible). Measurement data can prompt and track service improvements, and help demonstrate the contribution that services are making to those outside the department.

Donabedian $^{1}$ described the use of structural, process and outcome measures in healthcare. All three types of measures were developed for hospital pharmacy services at the International Pharmaceutical Federation (FIP) Global Conference on the Future of Hospital Pharmacy in 2009. ${ }^{2}$ It was also observed at the Global Conference that measures for hospital pharmacy services are usually developed in the following order: costs, then workload, then quality and safety (clinical). It was noted that it is important to develop quality and safety measures at the same time as measures for cost and workload. Reductions in costs and increases in workload should not be at the expense of quality and safety.
In preparation for the European Association of Hospital Pharmacists (EAHP) meeting on the European Statements of Hospital Pharmacy that took place in May 2014, ${ }^{3}$ a review of hospital pharmacy service performance measures was commissioned by the EAHP President. This work included an assessment of the current use of service performance measures and the draft European statement on this topic.

\section{A SURVEY ON SERVICE PERFORMANCE MEASURES}

A draft survey form was developed to determine whether service performance measures were being collected in European hospital pharmacies for four types of services: medicines distribution, medicines manufacturing, clinical services and financial services. Respondents were invited to indicate whether the specified hospital pharmacy services were provided and if any measurement data had been collected in the 12 months before the survey. A question was asked concerning whether the data had been shared outside the pharmacy department, with, for example, hospital managers, senior clinicians and accreditation programmes.

The draft survey form was piloted with four EAHP Scientific Committee members and some changes were made following their feedback. The survey was distributed via EAHP social media channels and by email directly to official delegates of EAHP member associations in March 2014.

A total of 190 survey forms were completed by hospital pharmacists in 36 countries. The most responses came from Spain (16), France (15) and Germany (15). There were single responses from Cyprus, Denmark, Luxemburg, Hungary, Macedonia, Russia and the Netherlands. Four responses did not identify the country of origin.

The results for medicines distribution services are shown in table 1 . The number of hospital pharmacies providing each service is shown as a percentage of the total number of responses (190). The number of hospital pharmacies collecting and sharing performance measurement data is shown as a percentage of the number providing the service. A total of 166 (82\%) hospital pharmacies supplied ward stock medicines, of which 122 (73.5\%) collected performance measurement data and 104 $(62.7 \%)$ shared these data outside the pharmacy.

The results for the medicines manufacturing and preparation services are shown in table 2. A total of $151(79.5 \%)$ hospital pharmacies manufactured non-sterile medicines, of which $106(70.3 \%)$ collected data and $64(42.4 \%)$ shared these data outside the hospital pharmacy. 
Table 1 Survey results on the measurement of medicines distribution services in 190 European hospital pharmacy departments

\begin{tabular}{lrrr}
\hline Service & Service provided & $\begin{array}{l}\text { Data collected in the } \\
\text { previous 12 months }\end{array}$ & $\begin{array}{c}\text { Data shared outside the } \\
\text { pharmacy department }\end{array}$ \\
\hline Supply of ward stock medicines & $166(82.4 \%)$ & $122(73.5 \%)$ & $104(62.7 \%)$ \\
Supply of medicines for named patients & $93(48.9 \%)$ & $75(80.6 \%)$ & $62(66.7 \%)$ \\
Supply of medicines for outpatients & $110(57.9 \%)$ & $67(60.9 \%)$ & $52(47.3 \%)$ \\
Supply of medicines for discharge & $86(45.3 \%)$ & $38(44.2 \%)$ & $29(33.7 \%)$ \\
\hline
\end{tabular}

Table 2 Survey results on the measurement of medicines manufacturing and preparation services in 190 European hospital pharmacy departments

\begin{tabular}{|c|c|c|c|}
\hline Service & Service provided & $\begin{array}{l}\text { Data collected in the } \\
\text { previous } 12 \text { months }\end{array}$ & $\begin{array}{l}\text { Data shared outside the } \\
\text { pharmacy department }\end{array}$ \\
\hline Sterile medicines manufacturing & $90(47.4 \%)$ & $71(78.9 \%)$ & $48(53.3 \%)$ \\
\hline Aseptic medicines preparation & $108(56.8 \%)$ & $85(78.7 \%)$ & $57(52.8 \%)$ \\
\hline Non-sterile medicines manufacturing & $151(79.5 \%)$ & $106(70.3)$ & $64(42.4 \%)$ \\
\hline Pharmaceutical quality assurance & $109(57.4 \%)$ & $69(63.3 \%)$ & $24(22.0 \%)$ \\
\hline
\end{tabular}

The results for financial services are shown in table 3. A total of $180(94.7 \%)$ hospital pharmacies provided medicine financial services, of which 173 (96.1\%) collected data and 154 (85.6\%) shared these data outside the pharmacy department.

The responses for clinical services are shown in table 4 . A total of 155 (81.6\%) hospital pharmacies provided drug information services, of which 68 (43.9\%) collected data and 43 $(27.7 \%)$ shared these data outside the pharmacy department.

\section{CONCLUSION AND SUMMARY}

Results for the survey indicate that the uptake of performance measurement in European hospital pharmacies is in the order observed at the FIP Global Conference: costs $>$ workload $>$ quality and safety (clinical). Apart from medicine cost data, there are relatively low rates of sharing these data outside the pharmacy department.
It can be argued that hospital pharmacy managers just provide the performance measures requested by hospital managers and that in many cases only medicine cost measurement data are requested. European hospital pharmacists along with other clinical professionals should continue to strive to ensure that other service performance data are always viewed alongside cost data, both inside and outside the pharmacy, in order to facilitate the best service management decisions.

The earlier FIP statements had a specific section on performance measurement. The new EAHP statements do not have a specific section on measurement. In EAHP standard 5.3, under patient safety and quality assurance, there is a broad statement:

In collaboration with other healthcare professionals, hospital pharmacists should ensure the development of appropriate quality assurance strategies for medication practices including the use of observation methodology, Medication Error Reporting

Table 3 Survey results on the measurement of financial services in 190 European hospital pharmacies

\begin{tabular}{lccc}
\hline Service & Service provided & $\begin{array}{l}\text { Data collected in the } \\
\text { previous 12 months }\end{array}$ & $\begin{array}{c}\text { Data shared outside the } \\
\text { pharmacy department }\end{array}$ \\
\hline Cost of medicines & $180(94.7 \%)$ & $173(96.1 \%)$ & $154(85.6 \%)$ \\
Cost of devices & $102(53.7 \%)$ & $96(94.1 \%)$ & $79(77.5 \%)$ \\
Cost of consumables & $80(42.1 \%)$ & $57(71.3 \%)$ & $37(46.3 \%)$ \\
Cost/number of pharmacy employees & $123(64.7 \%)$ & $92(74.8 \%)$ & $73(59.3 \%)$ \\
\hline
\end{tabular}

Table 4 Survey results on the measurement of clinical services in 190 European hospital pharmacy departments

\begin{tabular}{llcl}
\hline Services & Yes (\%) & $\begin{array}{l}\text { Data collected in the } \\
\text { previous 12 months (\%) }\end{array}$ & $\begin{array}{l}\text { Shared outside the } \\
\text { pharmacy department (\%) }\end{array}$ \\
\hline Clinical pharmacy interventions & $130(68.4 \%)$ & $100(76.9 \%)$ & $68(46.9 \%)$ \\
Medicines information & $155(81.6 \%)$ & $68(43.9 \%)$ & $43(27.7 \%)$ \\
Adverse reaction reports & $149(78.4 \%)$ & $81(54.4 \%)$ & $58(38.9 \%)$ \\
Medication error reports & $111(58.4 \%)$ & $87(78.4 \%)$ & $69(62.2 \%)$ \\
External accreditation & $100(52.6 \%)$ & $56(56.0 \%)$ & $42(42.0 \%)$ \\
\hline
\end{tabular}


Systems (MERS), and Clinical Incident Reporting System (CIRS) to detect errors and identify priorities for improvement.

To support this statement and the use of performance measurement, EAHP should further promote and improve the collection and use of measures to describe and improve hospital pharmacy services in Europe. Consideration should be given by EAHP to the following recommendations that they should:

- provide further support information on what, why, how and when performance measures should be collected and used in practice;

- provide a bench-marking site for hospital pharmacies to share measurement data, methods and analysis in order to improve services;

- provide an accreditation service for hospital pharmacies in Europe.
Acknowledgements The help and support of Roberto Frontini, EAHP President and Jennie De Greef, David Preece and Richard Price at EAHP in assisting with this work is acknowledged.

Competing interests None.

Provenance and peer review Commissioned; internally peer reviewed.

\section{REFERENCES}

1 Donabedian A. Evaluating the quality of medical care. 1966. Milbank Q 2005;83:691-729.

2 Cousins D. Global conference proceedings. The current status of monitoring medication practice. Am J Health Syst Pharm 2009;66(Suppl 3):S49-56. http://www. ajhp.org/content/66/5_Supplement_3/s49.full.pdf (accessed 22 Jul 2014).

3 European Association of Hospital Pharmacists. New European Statements of Hospital Pharmacy agreed by patients, healthcare professional and hospital pharmacists. EAHP, May 2014. http://www.eahp.eu/events/european-summit/summit-documents (accessed 22 Jul 2014). 